\title{
HIDROGEOMORFOLOGIA DA ILHA DA TRINDADE - CARACTERIZAÇÃO DA ÚNICA REDE HIDROGRÁFICA PERMANENTE NAS ILHAS OCEÂNICAS BRASILEIRAS
}

\author{
Cristiano Pena Magalhães Marques ${ }^{(a)}$, Antonio Pereira Magalhães Júnior ${ }^{(b)}$ Fabio Soares de \\ Oliveira $^{(c)}$ \\ (a) Mestrando do Programa de Pós Graduação em Geografia/IGC, UFMG, cristianommarques@ gmail.com \\ (b) Departamento de Geografia/IGC, UFMG, magalhãesufmg@yahoo.com.br \\ (b) Departamento de Geografia/IGC, UFMG, fabiosolos@gmail.com
}

\section{EIXO: SISTEMAS GEOMORFOLÓGICOS: ESTRUTURA, DINÂMICA E PROCESSOS.}

\section{Resumo}

Entre as ilhas oceânicas brasileiras, Trindade é a única que apresenta cursos d'água e nascentes perenes, embora apresente elementos desfavoráveis à ocorrência desses elementos, emergindo, portanto, como uma situação de destaque. Pretendendo ampliar essa discussão, o presente trabalho tem como objetivo caracterizar o quadro hidrogeomorfológico da ilha da Trindade, visando contribuir para a compreensão da configuração da rede hidrográfica e do relevo local. O trabalho foi elaborado com base em pesquisas bibliográficas, realização de trabalhos de campo e geoprocessamento. Nessa perspectiva, os resultados apontam para a presença de áreas que exibem características distintas em relação ao comportamento da drenagem superficial, ou seja, foram identificados três padrões, ou tipos de áreas de escoamento, além de 32 nascentes, que apresentaram vazões que variaram de incipiente (inferior a $1 \mathrm{~mL} / \mathrm{s}$ ), até $0,443 \mathrm{~L} / \mathrm{s}$, sendo a vazão média calculada de $0,048 \mathrm{~L} / \mathrm{s}$.

Palavras chave: ilha da Trindade; ilha ocêanica; hidrogeomorfologia; drenagem; nascentes.

\section{Introdução}

A natureza geológica e climática das ilhas vulcânicas, muitas delas com baixa pluviosidade anual e elevada pressão sobre os recursos hídricos, não favorece a ocorrência de elementos fluviais permanentes, já que, a presença de drenagens superficiais perenes está associada a fatores climáticos, geológicos e geomorfológicos específicos. Somado a isso, a incidência de intensos processos erosivos e de movimentos de massa, impulsionados pela presença de altas declividades, combinadas à baixa cobertura vegetal dos solos, significam outros obstáculos impostos em grande parte das ilhas vulcânicas (SANTAMARTA CEREZAL, 2013).

Em pesquisa bibliográfica realizada acerca dessa temática em algumas ilhas vulcânicas localizadas no Oceano Atlântico, é possível indicar que, nos arquipélagos de Açores e Madeira (Portugal), Canárias (Espanha) e Cabo Verde, todos localizados no Atlântico norte, apenas algumas ilhas do arquipélago de Açores apresentam águas superficiais lóticas de caráter permanente (SANTAMARTA CEREZAL, 2013; CYMBRON et al., 2006; GOMINHO, 2010; PRADA, 2000). 
Entre as ilhas oceânicas brasileiras, todas localizadas no Atlântico (sul e equatorial), Trindade é a única que apresenta cursos d'água e nascentes perenes. Nem mesmo Fernando de Noronha, que possui uma estrutura geológica bastante semelhante e uma área bem maior (cerca de $20 \mathrm{~km}^{2}$ ), apresenta esses elementos fluviais. Ou seja, a presença de água nos canais de drenagem de Fernando de Noronha, assim como na maioria das ilhas vulcânicas, está condicionada à ocorrência de eventos pluviométricos de maior relevância (MONTENEGRO et al., 2009).

Portanto, o caso da ilha da Trindade emerge como uma situação de destaque, uma vez que, embora apresente elementos desfavoráveis à ocorrência de drenagens superficiais permanentes, a ilha apresenta nascentes e cursos d'água que drenam ao longo de todo o ano. Entre esses obstáculos se destacam sua idade e sua área (emersa), tendo em vista que terrenos mais antigos e maiores tendem a apresentar redes de drenagem mais complexas, já que Trindade é considerada jovem e relativamente pequena, com uma idade de não mais que 3,5 milhões de anos, e uma área de cerca de $10 \mathrm{~km}^{2}$. Além disso, é importante salientar que Trindade experimentou mudanças ambientais drásticas, resultantes da ação humana, e que ela está inserida em um contexto climático do tipo tropical semi-úmido, de tendência a semi-árido, com baixa pluviosidade média anual.

Pretendendo ampliar essa discussão, o presente trabalho tem como objetivo caracterizar o quadro hidrogeomorfológico da ilha da Trindade, visando contribuir para a compreensão da configuração da rede hidrográfica e do relevo local. O trabalho foi elaborado com base em pesquisas bibliográficas, realização de trabalhos de campo e geoprocessamento. Para isso, buscou-se identificar os regimes de escoamento superficial, e o papel das águas superficiais na configuração geomorfológica da Ilha em termos de processos prioritários de erosão e sedimentação, e principais formas e formações superficiais resultantes. Ademais, almejou-se mapear e caracterizar as nascentes da ilha.

\section{2. Área de estudo}

A Ilha da Trindade (

Figura 1) representa o extremo oriental do território brasileiro, juntamente com o Arquipélago de Martin Vaz. Localizada no Oceano Atlântico sul, ela é a mais recente, heterogênea e topograficamente variada ilha oceânica brasileira (SCHAEFER; OLIVEIRA, 2015). Com superfície de cerca $10 \mathrm{~km}^{2}$ e localizada entre os paralelos $20^{\circ} 29^{\prime}$ e $20^{\circ} 32^{\prime} \mathrm{S}$ e entre os meridianos $29^{\circ} 21^{\prime}$ e $29^{\circ} 17^{\prime} \mathrm{W}$, Trindade está afastada por cerca de $1.200 \mathrm{~km}$ da linha de costa brasileira, sobre a Cadeia Vitória-Trindade.

Embora venha sendo visitada por navegadores, pesquisadores e naturalistas desde o século XVI, apenas no final do século XIX e início do século XX, a natureza vulcânica da Ilha da Trindade foi reconhecida. Almeida (2002) destaca que, já em 1797, Milet-Mureau reconheceu a presença de basaltos em Trindade, 
mas foi o geólogo Prior (1900), que examinando o material coletado pela expedição de James Ross (1839), indicou sua natureza vulcânica e sua semelhança com Fernando de Noronha (ULBRICH et al., 2004).

Foi, contudo, o trabalho de Almeida (1961), que forneceu a base fundamental do conhecimento geológico e geomorfológico de Trindade. Assim como havia realizado para Fernando de Noronha em 1955, a monografia publicada pelo autor oferece descrições minuciosas sobre as feições geomorfológicas e geológicas da ilha, além de apresentar seu respectivo mapa geológico (ULBRICH et al., 2004).

Apesar de possuir uma geomorfologia única no Brasil, de estruturas vulcânicas variadas e que se encontram bem preservadas (PIRES et al., 2013), além de representar a única ilha oceânica brasileira que dispõe de nascentes e cursos d'água perenes, vale ressaltar que há certa escassez de estudos geomorfológicos em Trindade: entre os principais trabalhos desenvolvidos na ilha, nenhum deles se propôs a abordar seus aspectos geomorfológicos com um maior nível de aprofundamento.

Soma-se a isso, conforme apurado em pesquisa bibliográfica, que embora a presença de água doce na Ilha da Trindade venha sendo documentada desde que seu território foi acessado pelos primeiros visitantes, constatou-se que ainda não há estudos focados, especificamente, nessa temática. Um importante indicativo desse quadro é que, até a presente data, não há nenhum trabalho científico publicado sobre as ilhas oceânicas brasileiras no principal periódico de geomorfologia brasileiro, a Revista Brasileira de Geomorfologia $^{1}$ e, tampouco, nos demais periódicos brasileiros mais bem qualificados pela Capes na área de Geografia (Qualis Periódicos - classificação A1): GEOgraphia, vinculado à Universidade Federal Fluminense) e Mercator, da Universidade Federal do Ceará.

Entre os trabalhos já publicados sobre Trindade, destacam-se os estudos realizados por Almeida (1961; 2002; 2006) que, de maneira geral, abordam a geologia da ilha; Alves (1998), que desenvolveu um ensaio geobotânico bastante abrangente para a área; Clemente (2006), que elaborou um estudo de caracterização de seus ambientes terrestres; Sá (2010), que classificou e mapeou os solos da ilha; Castro (2010), que desenvolveu estudo de geologia ambiental; Pires et al. (2013), que realizaram um estudo de geoconservação; Schaefer e Oliveira (2015), que apresentam os aspectos gerais do relevo de Trindade e Fernando de Noronha; e finalmente Machado (2016), que elaborou um estudo sobre as interações da avifauna com os substratos da ilha (rochas e solos).

\footnotetext{
${ }^{1}$ Motoki et al. (2012) desenvolveram trabalho sobre a geomorfologia submarina da Cadeia Vitória-Trindade, citando brevemente alguns aspectos relacionados à Trindade.
} 
XVII Simpósio Brasileiro

de Geografia Física Aplicada

I Congresso Nacional

de Geografia Física
OS DESAFIOS DA GEOGRAFIA FÍSICA NA FRONTEIRA DO CONHECIMENTO

Instituto de Geociências - Unicamp

Campinas - SP

28 de Junho à 02 de Julho de 2017

\section{Procediments Metodológicos}

Os resultados apresentados no presente trabalho são resultado de uma campanha de campo realizada entre os dias 17 de junho a 14 de agosto de 2015, a qual envolveu a permanência em Trindade por um período de aproximadamente 50 dias. Nesse sentido, buscou-se, em conformidade com as normas de segurança estabelecidas pela Marinha do Brasil, percorrer todos os trechos terrestres acessíveis da ilha, com o intuito de identificar as nascentes e cursos d'água que drenam seu território.

Uma etapa preliminar à campanha de campo foi realizada, em gabinete, com o objetivo de reunir as informações disponíveis para área, sobretudo bases cartográficas, mapeamentos e produtos de sensoriamento remoto, material esse que permitiu a marcação de pontos de checagem, os quais foram visitados em campo posteriormente. Ademais, a realização da etapa de campo contou com o auxílio de profissionais da Marinha do Brasil, conhecedores da área de estudo, que além de facilitarem a navegação em Trindade, indicaram locais passíveis de serem averiguados, conforme os objetivos da pesquisa.

Assim, segundo metodologia proposta por Felippe (2009), depois de identificados, os cursos d'água foram percorridos de jusante para montante, procedimento que possibilitou a localização das nascentes de Trindade.

Neste trabalho, concebe-se uma nascente "como um sistema ambiental em que o afloramento da água subterrânea ocorre naturalmente de modo temporário ou perene, e cujos fluxos hidrológicos na fase superficial são integrados à rede de drenagem" (FELIPPE; MAGALHÃES JR, 2013). Portanto, devido ao fato de caracterizarem-se pela passagem da água do meio subterrâneo para o superficial, definindo a espacialização da rede hidrográfica (FELIPPE, 2013), as nascentes foram selecionadas como eixo norteador da caracterização da rede hidrográfica da ilha. Desse modo, as nascentes foram localizadas, mapeadas e tiveram sua vazão calculada.

Nesse sentido, a localização das nascentes foi obtida via receptor GPS portátil modelo Garmim GPSmap 60CSx, através da marcação de pontos (Dátum WGS 1984 - Sistema de Coordenadas UTM, fuso 26K). Para reduzir o erro da marcação, estabeleceu-se como critério a retirada de uma média de no mínimo 20 pontos para o mesmo local, calculada automaticamente no aparelho. Dessa forma, o raio de imprecisão do aparelho sempre se manteve abaixo de dez metros, o que foi considerado satisfatório para os propósitos do trabalho.

Por sua vez, o procedimento de medida de vazão, tanto para as nascentes, quanto para os cursos d'água, baseou-se na coleta da água do fluxo em sacos plásticos, acompanhada da medição do tempo em cronômetro digital. A água coletada é, então, transportada para um medidor graduado, sendo realizada a leitura do volume. Para minimizar os possíveis erros de coleta, foram feitas no mínimo três medições em cada ponto amostrado (FELIPPE, 2009). 


\section{OS DESAFIOS DA GEOGRAFIA FÍSICA NA FRONTEIRA DO CONHECIMENTO \\ Instituto de Geociências - Unicamp \\ Campinas - SP \\ 28 de Junho à 02 de Julho de 2017}

Posteriormente os dados coletados foram tratados em gabinete. Nessa etapa, com o auxílio do software ArcGIS 10.1, e sempre em articulação com a literatura acadêmica pertinente ao tema, eles puderam ser especializados e analisados, o que permitiu a geração de tabelas e mapas, produtos que possibilitaram uma melhor leitura dos mesmos.

Destaca-se que, embora o tempo de permanência em Trindade tenha sido considerado suficiente perante os objetivos do trabalho, o fato de se tratar de uma área localizada em ambiente tropical, ou seja, que está susceptível à sazonalidade climática, deixa clara a necessidade de realização de campanhas de campo sistemáticas, com o intuito de monitorar a dinâmica de sua rede hidrográfica da ilha ao longo do tempo. Contudo, diante dos desafios logísticos inerentes à área de estudo, essa etapa não foi cumprida com a realização do presente trabalho, apesar disso, essa é uma lacuna que certamente deverá ser preenchida conforme os avanços nas pesquisas em Trindade são alcançados.

Embora Trindade ainda careça de estudos climáticos mais aprofundados e atualizados, Alves (1998) indica que os meses de abril, maio e junho são aqueles que apresentam os maiores índices pluviométricos (em torno de $100 \mathrm{~mm}$ mensais), sendo o mês de agosto e, em seguida, janeiro, os meses mais secos (em torno de $55 \mathrm{~mm}$ ). Deste modo, a etapa de campo foi realizada ao final da estação úmida.

\section{Resultados e discussões}

Almeida (1961) resume, de maneira precisa, a configuração da rede hidrográfica de Trindade. Segundo esse autor, numa pequena ilha oceânica como essa, sobretudo se as áreas mais elevadas do terreno forem suportadas por estruturas resistentes, dispostas na região central, a competição gerada na rede de drenagem leva cada vale a traçar seu caminho para o mar da maneira mais curta possível, o que geraria uma configuração de padrão radial, ou em "espinha de peixe". Nesse sentido, em tal modelo de evolução, os vales mais extensos estariam expostos à captura por parte dos mais curtos, uma vez que os últimos tendem a apresentar processos mais vigorosos em relação aos primeiros, em decorrência da maior declividade que costumam apresentar e, portanto, à maior energia presente no sistema.

Em síntese, com base nas propostas apresentadas (HACK E GOODLETT, 1960; HACK, 1960; CHARLTON, 2009), é possível indicar que o sistema fluvial de Trindade apresenta características típicas das zonas de produção de sedimentos, ou bacias de cabeceira. Ou seja, trata-se de uma área de elevada declividade, onde há a ocorrência de nascentes e canais de primeira e segunda ordem, esculpidos sobre substratos rochosos ou coluvionares (efêmeros e temporários no primeiro caso, e temporários ou permanentes no segundo), onde preponderam os processos de erosão, os quais fornecem grande carga sedimentar, de granulometria marcantemente grosseira, às calhas fluviais. 


\section{OS DESAFIOS DA GEOGRAFIA FÍSICA NA FRONTEIRA DO CONHECIMENTO \\ Instituto de Geociências - Unicamp \\ Campinas - SP \\ 28 de Junho à 02 de Julho de 2017}

Nessa perspectiva, a divisão hidrográfica de Trindade elucidou a presença de áreas que exibem características distintas em relação ao comportamento da drenagem superficial, ou seja, foram identificados padrões, ou tipos de áreas de escoamento ao longo da ilha. Nesse sentido, o primeiro padrão (i) constatado se refere à presença de grandes áreas de drenagem, que apresentam nascentes e canais fluviais com fluxos hídricos significativos, territórios esses com cerca de $1 \mathrm{~km}^{2}$ de extensão, e que, em valores relativos, correspondem a aproximadamente $10 \%$ da superfície total da ilha cada, representando, assim, as principais bacias hidrográficas de Trindade.

Em seguida, o segundo padrão (ii) está relacionado a áreas de dimensões inferiores ao padrão anteriormente mencionado, onde também há a presença de nascentes e cursos d'água, abrangendo bacias hidrográficas de áreas que variam entre 0,14 e $0,35 \mathrm{~km}^{2}$, ou seja, 1,4 a 3,5\% do território de Trindade, em valores relativos. O terceiro padrão (iii), assim como foi observado para o segundo (ii), também apresenta dimensões territoriais inferiores ao primeiro padrão $(i)$, com áreas entre 0,05 e $0,4 \mathrm{~km}^{2}$, entretanto, não há nesses casos a presença de nascentes. Portanto, a diferenciação entre esses dois últimos tipos se da, basicamente, pela contribuição de fluxos subterrâneos à drenagem, através da exfiltração nas nascentes, ou seja, o tipo $i i$, devido à presença de nascentes, apresenta fluxos perenes ou intermitentes e, por outro lado, os territórios do tipo iii são drenados exclusivamente por fluxos efêmeros, ou seja, gerados apenas por eventos pluviométricos mais significativos, devido à ausência de nascentes.

Diferentemente dos três padrões anteriormente descritos, o padrão $i v$ se refere a áreas de escoamento direto ao mar, ou o conjunto delas, as quais não foram classificadas como bacias hidrográficas devido à incipiência dos fluxos que abrangem, e ao reduzido tamanho que apresentam.

Portanto, foram identificadas $33^{2}$ bacias hidrográficas em Trindade (Tabela I; Figura 2), que correspondem às áreas descritas pelos padrões $i$, ii e iii, as quais juntas representam $69 \%$ do território total da ilha, em valores relativos, além de uma infinidade de pequenas áreas de escoamento direto (padrão $i v$ ) que, consequentemente, representam $31 \%$ da superfície emersa.

Logo, foi possível constatar que em Trindade há bacias hidrográficas que apresentam nascentes (padrões $i$ e ii), além de bacias hidrográficas, e outras áreas, denominadas áreas de escoamento direto ao mar (padrões iii e $i v$, respectivamente), que não apresentam esse elemento fluvial. Nesse sentido, através da Tabela II é possível verificar que foram identificadas $32^{3}$ nascentes na ilha, sendo $21 \mathrm{em}$ sua face leste e 11 na face oeste, distribuídas conforme a configuração espacial elucidada pela

\footnotetext{
2 Por se tratar de uma abordagem inédita, não existe uma toponímia consagrada para as bacias hidrográficas de Trindade, sendo assim, esses territórios foram numerados de 1 a 33, e serão citados no trabalho com base nessa numeração.

${ }^{3}$ Assim como foi destacado no caso das bacias hidrográficas, as nascentes foram numeradas de T01 a T33, e serão citados no trabalho com base nessa numeração, sendo que a T28 foi eliminada do trabalho por não se tratar de uma nascente.
} 
Figura 3.

Em relação à vazão das nascentes, destaca-se que oito delas apresentaram fluxos incipientes no momento de visita (T23, T24, T26, T27, T29, T30, T31 e T32) e, logo, não puderam ter suas vazões calculadas. Ademais, duas outras nascentes não puderam ter suas áreas de exfiltração acessadas (T07 e T19) e, dessa maneira, não foram totalmente caracterizadas, sendo que, nesses casos, o parâmetro vazão não pôde ser calculado apenas para a T19. Portanto, a

Tabela III apresenta a vazão das nascentes que tiveram seus fluxos mensurados.

Nesse sentido, segundo o sistema de classificação de nascentes de Meinzer (1927), Tabela IV, que utiliza como critério a vazão, proposta que ainda hoje é utilizada de maneira oficial nos Estados Unidos da América (FELIPPE, 2009), as nascentes de Trindade apresentam $6^{\mathrm{a}}$ (seis casos), $7^{\mathrm{a}}\left(10\right.$ casos) e $8^{\mathrm{a}}$ Magnitudes (16 casos: sete nascentes de vazão mensurável, oito casos de vazões desprezíveis e um caso de inacessibilidade) - Tabela V.

Assim, no caso de Trindade, as vazões variaram de incipiente (inferior a $1 \mathrm{~mL} / \mathrm{s}$ ), até $0,443 \mathrm{~L} / \mathrm{s}$, sendo a vazão média calculada, considerando as 32 nascentes identificadas, ou seja, todo o universo amostral, de $0,048 \mathrm{~L} / \mathrm{s}$. Por outro lado, quando consideradas apenas as nascentes que apresentaram fluxos capazes de serem mensurados (23 casos), essa média vai para 0,066 L/s. Portanto, conforme já destacado nesse trabalho, comparando as vazões das nascentes de Trindade com os resultados trazidos por outros autores que abordaram essa temática no território brasileiro (FARIA, 1997; ANDRADE PINTO ET AL., 2005; PANE E PEREIRA, 2005; JUNQUEIRA JÚNIOR, 2006; FELIPPE, 2009; FELIPPE, 2013), fica ainda mais evidente que a parcela continental do território brasileiro apresenta nascentes com vazões mais significativas que Trindade, do ponto de vista da vazão. De fato, a grande maioria das nascentes da ilha apresentou vazões inexpressivas, como foi possível observar pela análise de suas magnitudes (16 nascentes apresentam $8^{\mathrm{a}}$ Magnitude).

Contudo, vale ressaltar que as duas nascentes mais caudalosas da Ilha (T18 e T09) apresentam vazões que se mostram muito acima da vazão média calculada para algumas dessas áreas continentais brasileiras, o que reforça o argumento de que, analisando Trindade sob o contexto das ilhas oceânicas brasileiras, a Ilha emerge como uma situação de destaque. Soma-se a isso a presença de outras 11 nascentes que apresentaram vazões superiores a $10 \mathrm{ml} / \mathrm{s}$, com Magnitudes $6^{\mathrm{a}}$ e $7^{\mathrm{a}}$. 


\section{Figuras e Tabelas}

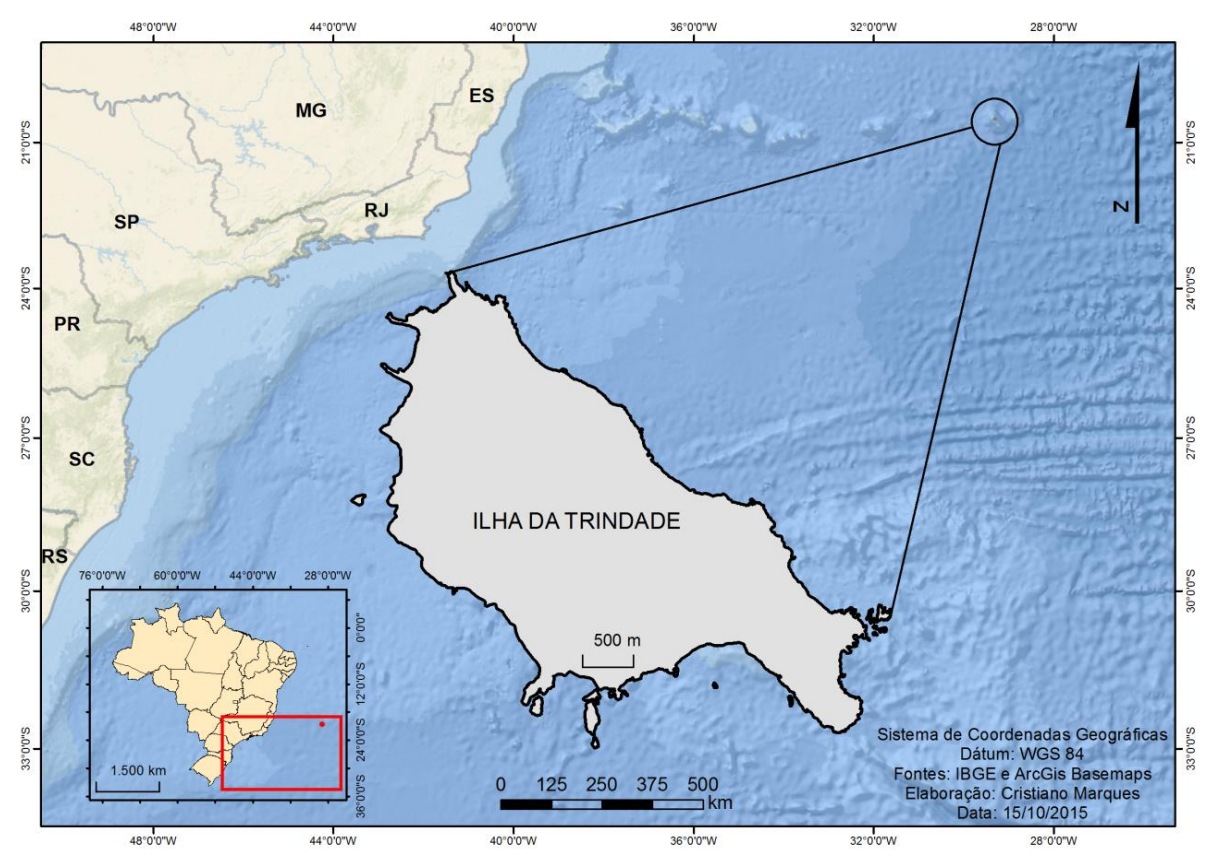

Figura 1 - Mapa de localização da Ilha da Trindade. Fonte: elaboração do autor.

Tabela I - Bacias hidrográficas principais. Fonte: Elaboração do autor.

\begin{tabular}{|c|c|c|c|c|c|}
\hline $\begin{array}{c}\text { Bacias } \\
\text { hidrográficas }\end{array}$ & Área $\left(\mathbf{k m}^{\mathbf{2}}\right)$ & $\begin{array}{c}\text { \% área total } \\
\text { da ilha }\end{array}$ & $\begin{array}{c}\text { Bacias } \\
\text { hidrográficas }\end{array}$ & Área $\left(\mathbf{k m}^{\mathbf{2}}\right)$ & $\begin{array}{c}\text { \% área total } \\
\text { da ilha }\end{array}$ \\
\hline $\mathbf{1}$ & 0,09 & $1 \%$ & $\mathbf{1 8}$ & 0,10 & $1 \%$ \\
\hline $\mathbf{2}$ & 0,23 & $2 \%$ & $\mathbf{1 9}$ & 0,78 & $8 \%$ \\
\hline $\mathbf{3}$ & 0,22 & $2 \%$ & $\mathbf{2 0}$ & 0,13 & $1 \%$ \\
\hline $\mathbf{4}$ & 0,06 & $1 \%$ & $\mathbf{2 1}$ & 0,24 & $2 \%$ \\
\hline $\mathbf{5}$ & 0,21 & $2 \%$ & $\mathbf{2 2}$ & 0,12 & $1 \%$ \\
\hline $\mathbf{6}$ & 0,07 & $1 \%$ & $\mathbf{2 3}$ & 0,11 & $1 \%$ \\
\hline $\mathbf{7}$ & 0,26 & $3 \%$ & $\mathbf{2 4}$ & 0,14 & $1 \%$ \\
\hline $\mathbf{8}$ & 0,10 & $1 \%$ & $\mathbf{2 5}$ & 0,34 & $3 \%$ \\
\hline $\mathbf{9}$ & 0,13 & $1 \%$ & $\mathbf{2 6}$ & 0,11 & $1 \%$ \\
\hline $\mathbf{1 0}$ & 0,74 & $7 \%$ & $\mathbf{2 7}$ & 0,25 & $2 \%$ \\
\hline $\mathbf{1 1}$ & 0,33 & $3 \%$ & $\mathbf{2 8}$ & 0,13 & $1 \%$ \\
\hline $\mathbf{1 2}$ & 0,40 & $4 \%$ & $\mathbf{2 9}$ & 0,10 & $1 \%$ \\
\hline $\mathbf{1 3}$ & 0,09 & $1 \%$ & $\mathbf{3 0}$ & 0,15 & $2 \%$ \\
\hline $\mathbf{1 4}$ & 0,05 & $1 \%$ & $\mathbf{3 1}$ & 0,29 & $3 \%$ \\
\hline $\mathbf{1 5}$ & 0,08 & $1 \%$ & $\mathbf{3 2}$ & 0,07 & $1 \%$ \\
\hline $\mathbf{1 6}$ & 0,16 & $2 \%$ & $\mathbf{3 3}$ & 0,35 & $3 \%$ \\
\hline $\mathbf{1 7}$ & 0,32 & $3 \%$ & TOTAL & $\mathbf{6 , 9 4}$ & $\mathbf{6 9 \%}$ \\
\hline
\end{tabular}


XVII Simpósio Brasileiro de Geografia Fisica Aplicada

I Congresso Nacional de Geografia Física
OS DESAFIOS DA GEOGRAFIA FÍSICA NA FRONTEIRA DO CONHECIMENTO Instituto de Geociências - Unicamp

Campinas - SP

28 de Junho à 02 de Julho de 2017

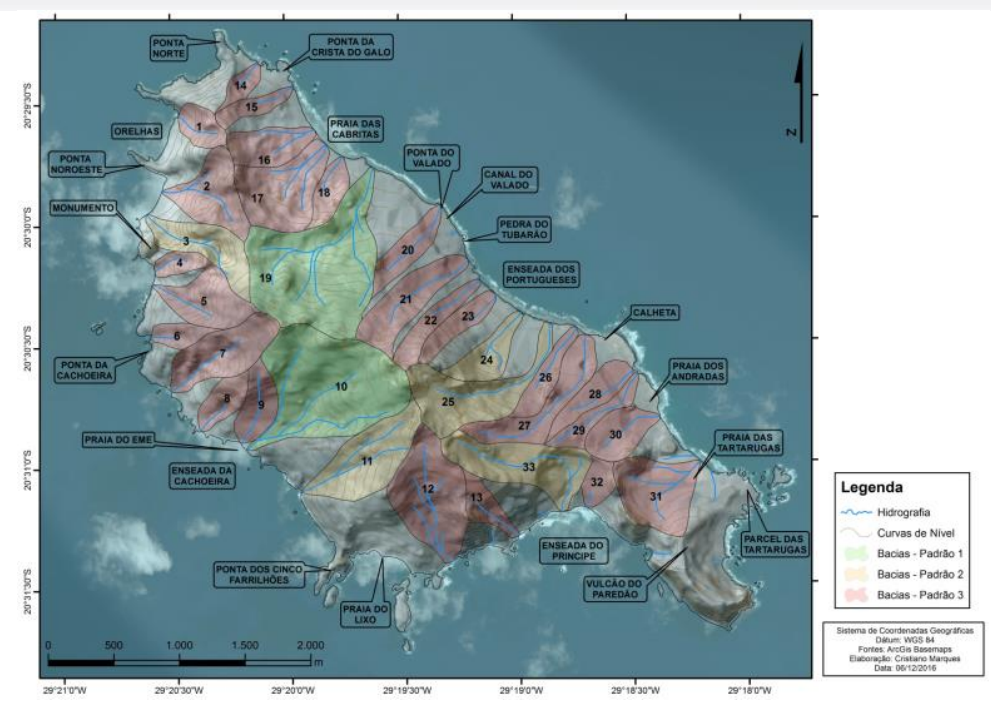

Figura 2 - Mapa da divisão hidrográfica da ilha. Fonte: Elaboração do autor.

Tabela II - Quantidade de nascentes por bacia hidrográfica/áreas de escoamento direto, separada por face da ilha. Fonte: Elaboração do autor.

\begin{tabular}{|c|r|}
\hline Bacia hidrográfica & $\begin{array}{r}\text { Número de } \\
\text { nascentes }\end{array}$ \\
\hline \multicolumn{2}{|c|}{ FACELESTE } \\
\hline 19 & 7 \\
\hline 24 & 6 \\
\hline 25 & 1 \\
\hline 33 & 6 \\
\hline Áreas de escoamento direto & 1 \\
\hline TOTAL - FACELESTE & $\mathbf{2 1}$ \\
\hline FACEOESTE & 1 \\
\hline 3 & 3 \\
\hline 10 & 5 \\
\hline 11 & 2 \\
\hline Áreas de escoamento direto & $\mathbf{1 1}$ \\
\hline TOTAL - FACEOESTE & $\mathbf{3 2}$ \\
\hline TOTAL DA ILHA \\
\hline
\end{tabular}

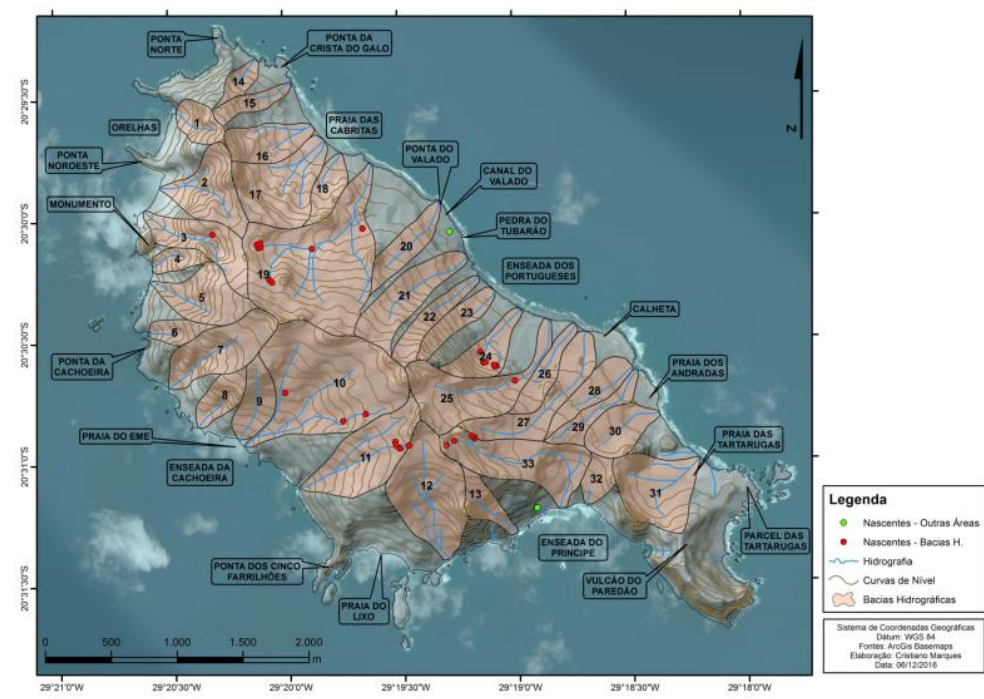

Figura 3 - Mapa da distribuição espacial das nascentes na ilha. Fonte: Elaboração do autor. 
Tabela III - Vazão das nascentes. Fonte: Elaboração do autor.

\begin{tabular}{|c|c|c|c|c|c|}
\hline Nome & $\begin{array}{l}\text { Vazão } \\
(\mathrm{ml} / \mathrm{s})\end{array}$ & Nome & $\begin{array}{l}\text { Vazão } \\
(\mathrm{ml} / \mathrm{s})\end{array}$ & Nome & $\begin{array}{l}\text { Vazão } \\
(\mathrm{ml} / \mathrm{s})\end{array}$ \\
\hline T01 & 10,94 & T09 & 350,21 & T17 & 53,28 \\
\hline T02* & 80,92 & T10 & 2,27 & T18 & 443,34 \\
\hline T03* & 80,92 & T11 & 4,90 & T20 & 20,37 \\
\hline T04* & 80,92 & T12 & 38,08 & $\mathbf{T 2 1}$ & 22,91 \\
\hline T05 & 5,99 & T13 & 36,50 & T22 & 1,47 \\
\hline T06 & 57,38 & T14 & 2,76 & T25 & 56,17 \\
\hline T07 & 109,77 & T15 & 27,01 & T33 & 3,90 \\
\hline T08 & 35,31 & T16 & 1,30 & & \\
\hline
\end{tabular}

Tabela IV - Proposta de classificação de nascentes - springs - segundo a vazão, de Meinzer (1927). Fonte: Extraído de Felippe, 2009.

\begin{tabular}{|c|c|c|}
\hline Magnitude & Vazão ( $\mathrm{ft}^{3} / \mathrm{s}$, gal/min, pint/min) & Vazão (L/s) \\
\hline $1^{\mathrm{a}}$ & $>100 \mathrm{ft}^{3} / \mathrm{s}$ & $>2.800 \mathrm{~L} / \mathrm{s}$ \\
\hline $2^{\mathrm{a}}$ & 10 a $100 \mathrm{ft}^{3} / \mathrm{s}$ & 280 a $2.800 \mathrm{~L} /$ \\
\hline $3^{\mathrm{a}}$ & 1 a $10 \mathrm{ft}^{3} / \mathrm{s}$ & $28 \mathrm{a} 280 \mathrm{~L} / \mathrm{s}$ \\
\hline $4^{\mathrm{a}}$ & $100 \mathrm{gal} / \mathrm{min}$ a $1 \mathrm{ft} 3 / \mathrm{s}$ & 6,3 a $28 \mathrm{~L} / \mathrm{s}$ \\
\hline $5^{\mathrm{a}}$ & $10 \mathrm{a} 100 \mathrm{gal} / \mathrm{min}$ & 0,63 a $6,3 \mathrm{~L} / \mathrm{s}$ \\
\hline $6^{\mathrm{a}}$ & $1 \mathrm{a} 10 \mathrm{gal} / \mathrm{min}$ & 63 a $630 \mathrm{~mL} / \mathrm{s}$ \\
\hline $7^{a}$ & $1 \mathrm{pint}$ a $1 \mathrm{gal} / \mathrm{min}$ & 8 a $63 \mathrm{~mL} / \mathrm{s}$ \\
\hline $8^{\mathrm{a}}$ & $<1 \mathrm{pint} / \mathrm{min}$ & $<8 \mathrm{~mL} / \mathrm{s}$ \\
\hline Magnitude 0 & \multicolumn{2}{|c|}{ Sem vazão (locais de fluxo passado/histórico) } \\
\hline
\end{tabular}

Tabela $V^{4}$ - Magnitude das nascentes de Trindade, segundo Meinzer (1927). Fonte: Elaboração do autor.

\begin{tabular}{|c|c|c|}
\hline \multicolumn{3}{|c|}{ Nascentes } \\
\hline 6 Magnitude - 63 a 630 mL/s & $7^{\mathrm{a}}$ Magnitude - 8 a $63 \mathrm{~mL} / \mathrm{s}$ & $8^{\mathrm{a}}$ Magnitude -8 a $63 \mathrm{~mL} / \mathrm{s}$ \\
\hline $\begin{array}{c}\text { T02, T03, T04, T07, T09, } \\
\text { T18 }\end{array}$ & $\begin{array}{c}\text { T01,T06, T08, T12, T13, } \\
\text { T15, T17, T20, T21, T25 }\end{array}$ & $\begin{array}{c}\text { T05, T10, T11, T14, T16, T19**, T22, } \\
\text { T24*, T26*, T27*, T29*, T30*, } \\
\text { T31*, T32*, T33 }\end{array}$ \\
\hline
\end{tabular}

\footnotetext{
$4 *$ Nascentes que não tiveram seus fluxos mensurados, devido à incipiência de seus fluxos; ** Nascente com área de exfiltração inacessível, onde não houve medição de vazão.
} 


\section{Agradecimentos}

Ao CNPq, por concessão de bolsa de mestrado, aos grupos de pesquisa Geografia e Recursos Hídricos e TRADO (IGC/UFMG-CNPq), à Marinha do Brasil, à SECIRM e ao PROTRINDADE.

\section{Bibliografia}

ALMEIDA, F. F. M. Geologia e Petrologia da ilha da Trindade. Serviço Gráfico do Instituto Brasileiro de Geografia e Estatística, Rio de janeiro, 1961, 197 p.

ALMEIDA, F. F. M. Ilha de Trindade - registro de vulcanismo cenozoico no Atlântico Sul. In: SCHOBBENHAUS, C.; CAMPOS, D. A.; QUEIROZ, E. T.; WINGE, M.; BERBET-BORN, M. L. C. (Eds.). Sítios geológicos e paleontológicos do Brasil. $1^{\text {a }}$ ed.: Comissão Brasileira de Sítios Geológicos e Paleobiológicos, Brasília, DF, 2002, p.369-377.

ALMEIDA, F. F. M. Ilhas oceânicas brasileiras e suas relações com a tectônica atlântica. Terrae Didatica, v. 2, n. 1, p. 3-18, 2006.

ALMEIDA, F. F. M. Ilha de Trindade - registro de vulcanismo cenozoico no Atlântico Sul. In: SCHOBBENHAUS, C.; CAMPOS, D. A.; QUEIROZ, E. T.; WINGE, M.; BERBET-BORN, M. L. C. (Eds.). Sítios geológicos e paleontológicos do Brasil. $1^{\text {a }}$ ed.: Comissão Brasileira de Sítios Geológicos e Paleobiológicos, Brasília, DF, 2002, p.369-377.

ALVES, R. J. V. Ilha da Trindade \& Arquipélago Martin Vaz - um ensaio geobotânico. Serviço de Documentação da Marinha, Rio de Janeiro - RJ, 1998, 144p.

ANDRADE PINTO, L.V.; BOTELHO, S.A.; DAVIDE, A.C.; FERREIRA, E. Estudo das nascentes da bacia hidrográfica do ribeirão Santa Cruz, Lavras, M.G.; Scientia Forestalis, nº5, p.197-206, 2004.

CASTRO, J. W. A. Ilhas oceânicas da Trindade e Fernando de Noronha, Brasil: uma visão da Geologia ambiental. Revista de Gestão Costeira Integrada - Journal of Integrated Coastal Zone Management, v. 10, n. 3, p. 303-319, 2010.

CHARLTON, R. O. Fundamentals of Fluvial Geomorphology. Londres: Routledge, 1 Ed., 2007.

CLEMENTE, E. C. Ambientes terrestres da Ilha da Trindade, Atlântico Sul: caracterização do solo e do meio físico como subsídio para a criação e uma unidade de conservação. Doutorado (tese do Programa de Pós Graduação em Solos e Nutrição de Plantas). Universidade Federal de Viçosa, Viçosa - MG, 2006, 167p.

CYMBROM, R.; PACHECO, D.; GONÇALVES, V.; CABRAL, M.; CRUZ, J. V.; RAPOSEIRO, P.; COSTA, A.; MARQUES, H.; DOMINGOS, M.; NUNES, J. C.; COUTINHO, R. Monitorização da qualidade das águas superficiais das ilhas de Santa Maria e São Miguel da Região Autónoma dos Açores. In: Proceedings $8^{\mathbf{0}}$ Congresso da Água. 2006. p. 13-17.

FARIA, A.P. A dinâmica de nascentes e a influência sobre os fluxos nos canais. A Água em Revista, Rio de Janeiro, v. 8, 1997.

FELIPPE, M. F. Caracterização e tipologia de nascentes em unidades de conservação de Belo Horizonte - MG com base em variáveis geomorfológicas, hidrológicas e ambientais. Mestrado (dissertação do Programa de Pós Graduação em Geografia - área de concentração: Análise Ambiental). Universidade Federal de Minas Gerais, Belo Horizonte - MG, 2009, 275p. 
FELIPPE, M. F. Gênese e dinâmica de nascentes: contribuições a partir da investigação hidrogeomorfológica em região tropical. Doutorado (tese do Programa de Pós Graduação em Geografia - área de concentração: Análise Ambiental). Universidade Federal de Minas Gerais, Belo Horizonte - MG, 2013, 254p.

FELIPPE, M. F.; MAGALHAES JR., A. P. Conflitos conceituais sobre nascentes de cursos d'água e propostas de especialistas. Revista GEOgrafias (UFMG), v. 9, p. 70-81, 2013.

GOMINHO, M. F. A. Gestão dos Recursos Hídricos no Processo de Desenvolvimento Sustentável de Cabo Verde: uma proposta. Mestrado (dissertação do programa de pós-graduação em Gestão de Empresas). ISCTE, Business School, Instituto Universitário de Lisboa, Departamento de Gestão. Lisboa, Portugal, 2010, 114p.

HACK, J. T. Interpretation of erosional topography in Humid Temperate regions. American Journal of Science, 188, p 80-97, 1960.

HACK, J.T.; GOODLETT, J.C. Geomorphology and forest ecology of a mountain region in the central Appalachians. Denver, U.S. Geol. Surv, p. 66, 1960.

JUNQUEIRA JÚNIOR, J. A. Escoamento de nascentes associado à variabilidade espacial de atributos físicos e uso do solo em uma bacia hidrográfica de cabeceira do Rio Grande - MG. Mestrado (dissertação do Programa de Engenharia Agrícola - área de concentração: Irrigação e Drenagem). Universidade Federal de Lavras, Lavras MG, 2006, 86p.

MACHADO, M. R. Interação avifauna-substratos na Ilha de Trindade, Atlântico Sul, Brasil. Mestrado (dissertação do Programa de Pós Graduação em Geografia - área de concentração: Análise Ambiental). Universidade Federal de Minas Gerais, Belo Horizonte - MG, 2016, 92p.

MEINZER, O. E. Large springs in the United States. Water Supply Paper 557 - U.S. Government Printing Office. Washington - DC, USA, 1927.

MONTENEGRO, A. A.; RIBEIRO, M. R.; MONTENEGRO, S. M., CORRÊA, M. M.; SANTOS, T. E. Potencialidades hídricas superficiais de Fernando de Noronha, PE, e alternativas para incremento da oferta. Revista Brasileira de Engenharia Agrícola e Ambiental, v. 13, p. 931-939, 2009.

PANE, E.; PEREIRA, S. Y. As fontes em Itamonte, sul de Minas Gerais - uma contribuição para o entendimento das relações entre água superficial e subterrânea. Águas subterrâneas. v. 19. n. 1, p. 1-14, 2005.

PIRES, G. L C.; MANSUR, K. L.; BONGIOLO, E. M. Geoconservação da Ilha da Trindade: Principais Aspectos e Potencial de Uso. Anuário do Instituto de Geociências, v. 36, n. 2, p. 96-104, 2013.

PRADA, S. L. R. N. Geologia e recursos hídricos subterrâneos da ilha da Madeira. Doutorado (dissertação do programa de pós-graduação em Geologia). Universidade da Madeira, Funchal, Portugal, 2000, 352p.

SÁ, M. M. F. Caracterização ambiental, classificação e mapeamento dos solos da ilha da Trindade, Attântico Sul. Mestrado (Dissertação do Programa de Pós-Graduação em Solos e Nutrição de Plantas), Universidade Federal de Viçosa, Viçosa - MG, 2010, 58 p.

SANTAMARTA CEREZAL, J. C. Hidrología y recursos hídricos en islas y terrenos volcánicos: Métodos, Técnicas y Experiencias en las Islas Canarias. Colegio de Ingenieros de Montes, 2013.

SCHAEFFER, C. E. G. R.; OLIVEIRA, F. S. Brazil in the South Atlantic: The Fernando de Noronha and Trindade Archipelagos. In: VIEIRA, B. C.; SALGADO, A.; SANTOS, L. (org.) Landscapes and Landforms of Brazil. 1 ed. Netherlands: Springer, 2015, p. 65-78. 


$\begin{aligned} & \text { XVII Simpósio Brasileiro } \\ & \text { de Geografia Fisica Aplicada }\end{aligned}$
$\begin{aligned} & \text { I Congresso Nacional } \\ & \text { de Geografia Física }\end{aligned}$

ULBRICH, M. N. C.; MARQUES, L. S.; LOPES, R. P. As ilhas vulcânicas brasileiras: Fernando de Noronha e Trindade. In: MANTESSO-NETO, V., BARTORELli, A., CARNEIRO, C. D. R., NEVES, B. B. B (eds.) Geologia do Continente Sul-Americano: evolução da obra de Fernando Flávio Marques de Almeida. São Paulo: Beca, 2004, p.555-573. 